\title{
Psychological well-being and quality of life in patients treated for thyroid cancer after surgery
}

\section{Relación entre bienestar psicológico y calidad de vida en pacientes con tratamiento para el cáncer de tiroides con condición postquirúrgica}

\author{
Mónica María Novoa Gómez \\ Rochy M. Vargas Gutiérrez \\ Shirley Alexandra Obispo Castellanos \\ Máryori Pertuz Vergara \\ Yady Karina Rivera Pradilla \\ Grupo de Investigación en Psicologia y Salud \\ Pontificia Universidad Javeriana, Bogotá. Colombia
}

(Rec: 03 marzo 2009 / Acep: 10 marzo 2010)

\begin{abstract}
The main goal is to assess psychological well-being and quality of life in 75 patients with post-surgical treatment for thyroid cancer. A descriptive correlational methodology was used in order to perform this task. Psychological well-being was assessed with the Index of Psychological Well-being developed by Dupuy et al., (1984) and Quality of Life was assessed with the Quality of Life Questionnaire SF-36 Health (Ware \& Sherbourne, 1992). The instruments were applied to each patient during an interview. Results suggested a high, positive and directly proportional correlation between time after thyroidectomy and the degree of Psychological Well-being and Quality of Life reported by patients. Results also showed a high correlation (significant at the $99 \%$ level) between the two instruments used.
\end{abstract}

Keywords: Quality of life, Thyroid Gland, Psychological Well-being, Cancer, Thyroidectomy.

\section{Resumen}

Se evaluó el bienestar psicológico y la calidad de vida en 75 pacientes posquirúrgicos y con tratamiento para el cáncer de tiroides. Con una metodología descriptiva correlacional. El bienestar psicológico se evaluó con el índice del Bienestar psicológico desarrollado por Dupuy et al., (1984) y la calidad de vida se evaluó con el Cuestionario de Calidad de Vida en Salud SF-36 (Ware \& Sherbourne, 1992). Cada paciente se entrevistó personalmente en una sesión, en la cual se aplicaron los dos instrumentos. En los resultados se encontró una alta correlación positiva y directamente proporcional entre el tiempo después de la tiroidectomía y el grado de bienestar psicológico y calidad de vida que reportan los pacientes, también se evidenció una correlación alta (significativa al 99\%) entre los dos instrumentos utilizados, en general.

Palabras Clave: Calidad De Vida, Glándula Tiroides, Bienestar Psicológico, Cáncer, Tiroidectomía.

In case you are interested in correspondence relating to this article, please contact the first author on the following e-mail: mmnovoa@javeriana.edu.co 


\section{Introduction}

Quality of life is a complex concept that encompasses objective and subjective dimensions such as food, housing, the opportunity to study, health and perceptions about them (Carpio, Pachecho, Flores \& Canales, 2000; Novoa, Cruz, Rojas, Wilde, 2003). Diener (1984, cited by Rodriguez, 1998) has defined quality of life as a subjective view of the extent to which happiness and satisfaction have been achieved, or as a sense of personal, subjective view that has also been considered closely related to certain biological, economic, psychological and social factors (Garavito, 2001; Gomez Villegas de Posada, Barrera \& Cruz, 2007).

The World Health Organization tried to embrace the complexity of the term "Quality of Life", defining it as "the perception that an individual has as about their place in their own existence, in the context of culture and their value system in which they live and on relation to their objectives, their expectations, their norms, their concerns, etc. This is a very broad concept which is influenced by complex ways and complex issues than physical health of the individual factors, his psychological state, level of independence, their social relationships and their relationship with the environment" (World Health Organization [WHO], 2005).

Psychology's view is that well-being means having good emotional and mental health as pillars of quality of life in a particular individual (López \& Torres, 2001) in diverse contexts (Novoa-Gómez \& Ballesteros, 2006). From this perspective, psychological well-being includes the way people used to evaluate their lives in the present and in the past; so, these assessments cover the emotional reactions of people to events, moods, and judgments related to the way they live their own lives (Diener, 1984, cited by RodriguezMarín 1998, Diener, Oishi, \& Lucas, 2003).

Therefore, well-being is a dynamic result which is in constant change (Ballesteros, Botero, Caycedo, Gutiérrez, Hermida, Medina, Motaña \& Otero, 2003), established in the evaluation of functional or contingent relationships among the individuals, their conditions of life and their environment, as established by Skinner (1990, cited by Caycedo \& Ballesteros, 2002), when explaining the role of well-being in the prediction and control of both environment and behavior as the interaction between the variables identified and known by the individual, such as situational factors and structural context and the organism.

Psychological support and treatment of cancer patients are key issues in all effective and humane therapeutic programs, considering the variety and difficulty of the situations this kind of patients go through, with the adjustments that individuals must make in their own lives after diagnosis, treatment or exacerbations and remissions that occur during their disease (Goepp \& Hammond, 1977) and throughout different stages of the illness (Novoa-Gómez, Moreno, Garcia, Leguizamón \& Castaño, 2006).
Health status is a determinant of quality of life because it is one of the components involved in establishing psychological well-being, but even more than objective health (physical impairment or medical conditions in general), it is the subjective interpretation made by the patients about their health which affects their emotional adjustment. Thus, "It is the individual perception of the situation, which generates the impact on health" according to different authors (Diener et al., 2003).

From the above, the importance of an approach to the concept of quality of life that includes objective and subjective aspects (García \& Viniegra-González, 2000) and permits a proper connection between them (Gómez, et al., 2007) becomes clear.

This way of thinking about health and well-being makes it is possible to establish three relevant dimensions which are: 1) the physical dimension, seen as the perception of physical condition or health, and also understood as the absence of disease, the symptoms produced by it and the adverse effects of treatment; 2) the psychological dimension, which involves understanding the cognitive and emotional status of individuals, including personal beliefs, spiritual and religious meaning of life and attitude towards suffering; and 3) the social dimension, understood as the individual's perception of interpersonal relationships, social roles in life, the need for family and social support, patient-physician relationship and job performance (Diener, et al., 2003).

In global terms, quality of life represents general conditions of public health, but when it is a question of persons that suffer from a disease or are in treatment, indicators of malfunction or disability related to the process the individual is undergoing are used. This process is defined in the area of health as " the capacity that the patients have to handle and take their lives of agreement to their evaluation related to their medical condition" (López \& Torres, 2001).

A disadvantage specific to cancer in contrast to other diseases, which is also a high risk, is the social stigma for the patients. For them, it is not only the presence of the cancer that can affect the quality of life of both the patient and of their relatives, but in addition, it can affect the perception of limitations and negative consequences presented by some of their treatments (chemotherapy, surgery, etc.), even though in some occasions patients can feel supportless or simply isolated on the treatment process (Goepp \& Hammond, 1977).

Some types of cancer may change the physiognomy of patients or create several and evident deformations. These changes, both in their functionality and in their aesthetics, may arise from the tumor itself or from the surgical processes used as treatment (for an detailed analysis please see Goepp \&Hammond, 1977), since therapeutic procedures and processes affect physical areas which are very visible areas of the organism and any modification in them will be visible to everyone. The processes of social stigmatization 
can be thus increased and, in some cases, the same will happen to feelings of embarrassment related to being a cancer patient.

In patients with thyroid pathologies (thyroxine (T4) and Triiodothyronine (T3) (Wiegel, Macdonald, Haller, McDougall, 2004), in addition to aesthetic changes, patients may also experience endocrine and psychological problems associated with hormone deficits secondary to thyroid surgery, and mood changes arising from this deficit such increased irritability, and so on. The patient will therefore need to use various treatments to replace the functions of these glands; treatments that have diverse effects on the patient and may produce high levels of stress, tension and concern over the uncertainty of treatment outcomes, and therefore the need for studies on these topics are most evident (Barreda, 2005). Therefore, the disease- just like health-consists not only of the physical ailments of the patient, but it involves elements of biological, social, psychological and emotional realities, among others. These are involved in the assessment made of the patient, and related to their situation and have effects on the perception of quality of life (Ángel 1977, cited by Novoa, 2004; Luria, 1944, cited by Grau \& Pörtero, 1987).

According to the NCI (for its initials in English, which is the lead agency of the U.S. government for research on cancer), thyroid cancer attacks women more often than men and usually occurs in people 25 to 65 years of age. Patients who received radiation in infancy and childhood to treat benign conditions of the head and neck such as dilation of the thymus, acne, or tonsillar enlargement, have a higher risk of suffering from cancer and other thyroid abnormalities. In this group of patients, malignant thyroid tumors start to appear from five to twenty years after radiation. Other risk factors in the evolution of thyroid cancer are having a history of goiter, family history of thyroid disease, being a female and Asian race. The incidence of this disease has been increasing over the past decade.

In the last two decades, the incidence of problems related to cancer has increased remarkably on Latin America and the Caribbean, to the point that in countries like Colombia, it is the second leading cause of death (Robles \& Galanis, 2002). Also, according to some studies conducted in 2004 by Piñeros \& Murillo, the number of patients with all types of cancer in Colombia during 2004 was 213.7 cases per 100,000 males and 212.9 cases per 100,000 women, for a total of 426.6 cases per 100,000 Colombians .

With regard to thyroid cancer, although the incidence of cases is not one of the highest among all the types of cancer existing, it is the most common of cancers of the endocrine glands, presenting 214 new cases during 2003. Most have presented in women between 45 and 49 years of age, so is also important to emphasize that the most common treatment for this disease was the surgery for tumor resection or partial excision or total gland extraction (Rada, Garrido, Osorio \& Murillo, 2004).

The prognosis for differentiated carcinoma is better for patients younger than 40 years without extracapsular extension or vascular invasion. Age by itself appears to be the most important prognostic factor. According to the National Cancer Institute in the USA, a retrospective surgical series of 931 patients with differentiated thyroid cancer not previously treated, found that female gender, multifocality, and complication of regional nodes are favorable prognostic factors. Adverse factors include age over 45 years, follicular histology, spread outside the thyroid (T4) and distant metastases (Sociedad Americana del Cáncer, 2004). Occasionally, there may be other primary thyroid tumors as sarcomas, lymphomas, teratomas and epidermoid carcinomas and metastases of other cancers, especially lung, breast and kidney (Sociedad Americana del Cáncer, 2004).

From this, there are four main types of thyroid cancer (according to the appearance of cancer cells under a microscope), which include: papillary cancer, follicular, medullary and anaplastic (Sociedad Americana del Cáncer, 2004).

As mentioned before, some types of thyroid cancer grow much faster than others, therefore, the probability of recovery (prognosis) depends on the type of thyroid cancer and if it is found in the thyroid gland or has spread to other parts of the body (stage), of the patient's age and overall health. The prognosis is better for patients under 40 years of age with cancer that has not spread beyond the thyroid.

In some cases there has been a detection of an inherited abnormal gene in patients suffering from thyroid cancer. Scientists have developed tests to identify carriers of this genetic defect long before the cancer appears. It is therefore very important that patients and their family members (children, grandchildren, parents, brothers, sisters, nieces and nephews) take precautions against it, and consult a physician who can provide them with available evidence in order to determine the presence of this defective gene and provide assistance to the patients and their family. Family members, including young children who do not have cancer but who have this defective gene, can decrease the chances of developing medullary thyroid cancer through surgery to remove innocuous benign thyroid gland masses (thyroidectomy) (Instituto Nacional de Cáncer de Estados Unidos, 2005).

To estimate the functional status of patients with cancer or any chronic illness, Rodriguez (1998), mentioned that the quality of life is a multidimensional construct that has four domains, including:

a) Functional status, which is the ability of individuals to develop a series of activities that allow them to remain in a self-sufficient state; it is measured through self-care, mobility and physical activity;

b) Symptoms related to the disease and treatment, reflecting that physical symptoms in the disease process and 
treatment are different depending on the type of disease, its stage and many other factors; in the case of cancer patients, symptoms such as pain, shortness of breath, fatigue, physical discomfort, constipation, diarrhea, nausea and sleep disorders are most often marked. Each symptom can be evaluated using indicators that represent presence or absence, frequency, severity and / or duration;

c) Social functioning is evident in the interactions between family, friends, community and work context, in sum the social adaptation of the individual, and is manifested in patients with clinical disorders as a result of functional limitations due to pain, fatigue, fear, fear of embarrassment or disability, feelings of discomfort and fear of contagion (Malagón, Galán \& Potón, 1999).

Therefore, when we talking about quality of life in the chronically ill, scientists have considered the patient's level of functional status, i.e., the extent to which patient's adapts to the presence of painful symptoms or diminished capabilities, how they are handled in the cognitive, emotional and behavioral psychological components, and what their level of social adaptation and employment is. These are all valued by the patients themselves because the diagnosis of cancer changes the way people see their selves and their lives, and even the way in which they plan programs developed for their own life (Tomich \& Helgeson, 2002).

Although cancer is an important event for those who suffer from it, it also brings an opportunity for growth. Despite the difficulty posed by treatments, thousands of survivors say that the experience led them to make major changes in their lives, from taking the time to appreciate each new day, learn how to take better care of themselves, or how to give value to the care offered to them by others.

\section{Method}

\section{Design}

It was a non-experimental descriptive correlational study, to assess the quality of life and psychological wellbeing in postsurgical patients with thyroid cancer. This investigation and its area of application are within the clinical field, so the objective was to describe the quality of life and psychological well-being of individuals by focusing on the quantitative measurement of different dimensions of quality of life, described in the SF-36, and dimensions of psychological well-being assessed in the Index of Psychological Well-being created by Dupuy (1984, cited by Badia, Salamero \& Alonso, 2002).

After measuring the different dimensions which play a role in the phenomenon described here, a correlational analysis was conducted in order to establish the relationships between these variables; the explanatory value is facilitated because of the correlation of data obtained by descriptive analysis.

\section{Participants}

We performed a subject-sampling rate. Participation was voluntary in the remaining informed consent for the patient to the institution. Participants in this study were seventy-five adults who have received surgical treatment for thyroid cancer over the past three years.

\section{Variables}

Quality of life: understood as a personal opinion or perception of the extent to which happiness and satisfaction have been achieved, as well as a sense of a personal, subjective view that has also been considered to be closely related to certain biological, economic, psychological and social factors, according to Diener (1984, cited by Rodríguez- Marín, 1998).

Psychological well-being: psychological well-being is a construct that expresses the positive and constructive thinking of people about themselves, which is defined by its subjective nature and includes aspects such as physical functioning, psychological and social elements (Garcia \& Viniegra-González, 2000).

Thyroid Cancer: Thyroid cancer is a tumor originating in cells of the thyroid gland. Its subtypes depend on the type of cell in which it originated. These tumors may present as a bulge in the front and bottom of the neck, usually painless and with slow growth.

After several years of evolution, in very advanced stages they may invade surrounding structures causing pain, difficulty breathing, swallowing and dysphonia. In some cases, the tumor can be made evident by a distant spread (metastasized) but it may not cause clinical signs, depending on the organ affected (Barreda, 2005).

\section{Instruments}

Health Quality of Life Questionnaire SF-36 (CVS): was used as the first instrument; reliability and cultural adaptation of the Quality of Life Questionnaire on Health SF-36 (CVS) (Ware \& Sherbourne, 1992) was calculated and validated by García \& Lugo (2002) in health institutions in Medellin (Colombia).

Variables addressed by the Quality of Life on Health Questionnaire SF-36 (Ware \& Sherbourne, 1992) on health status are:

1. Physical Function $(F F)$ : It is associated with activities such as walking, running or lifting or moving heavy objects. Stoop, kneel, squat reach, bathing or dressing. FF1) intensive activities such as running or lifting heavy objects; FF2) Moderate activities such as moving a table, mopping, washing, FF3) Lifting or carrying shopping bags, FF4) Going up in a multi-storey staircase; FF5) Upload a floor ladder; FF6) crouch, kneel or squat reach; FF7) Walking more than a kilometer; FF8) Walking half a kilometer; FF9) Walking one hundred meters; FF10) bathing or dressing. 
2. Physical Performance (DF): Measures the limitation or difficulty in doing any type of work or other activities. DF1) Less time spent on work or other activities; DF2) do less activities than those wanted to do; DF3) Limitation on the type of work or activities; DF4) Difficulties to work or other activities.

3. Physical pain $(D L)$ : This variable examines the intensity of physical pain, while the interference of pain to exercise this work. DL1) intensity of physical pain; DL2) Interference of physical pain in the job.

4. General Health (SG) is measured qualitatively as excellent, good, fair or poor. SG1) Your health is: excellent, good, fair, poor, SG2) I think I get sick easier than others; SG3) I am as healthy as anyone; SG4) I think my health will deteriorate; SG5) My health is excellent.

5. Vitality (VT) is associated with vitality and energy expressed by the person suffering from the disease. VT1) Feeling vibrant, VT2) Have lots of energy; VT3) Feeling exhausted, VT4) Feeling tired.

6. Social Function (SF): This variable includes the frequency and time where health problems have interfered with the implementation of various social activities. FS1) frequency with which health problems interfere with social activities; FS2) Time that health problems interfered with social activities.

7. Emotional Performance (DE): It is associated with the relationship between activities and emotional problems due to the disease. DE1) Less time for emotional problems; DE2) Make fewer activities for emotional problems; D3) Juvenile care activities by emotional problems.

8. Mental Health (SM) are important aspects such as mood and the nervous state of the patient. SM1) was very nervous; SM2) Feeling with the mind decayed; SM3) Feel calm and serene; SM4) Feeling sad too; SM5) Feeling happy.

9. Health change in time (CT): It describes the health status compared with a year ago.

This is a generic instrument of health status, which includes eight concepts summarized in physical and mental, which also includes a self-assessment of health change over the last year. Thirty-six items translate into eight scales that comprise between two and ten items and two summary measures involving five dimensions: physical and occupational therapy and functional abilities, psychological status and well-being, social interaction, vocational status and / or economic factors status and spiritual / religious.

The Psychological Well-Being Index (Dupuy, 1984, cited by Badia, et al., 2002).

The psychological well-being index was developed by Dupuy in 1984, contains 22 items divided into the following six dimensions: anxiety, depression, positive mood, vitality, self-control and general health. The items can be answered on a Likert scale with six response categories classified according to the degree, intensity or frequency of items in the last week (Badia, et al., 2002).

The Psychological Well-Being Index is composed of six dimensions divided into 22 items. The first is anxiety which refers to the discomfort caused by nervousness, the degree of tension or relaxation that creates a problem for patients, caused by their health problems.

The second is related to depression, and is understood as a physiological imbalance that disturbs the individual's vision of reality, causing serious episodes of sadness, reluctance, anxiety, and many features that do not allow the individual to develop their self.

The third is the positive mood, which, broadly speaking, relates to the happiness and satisfaction with, and interest in, life. The fourth category is the high levels of vitality or energy, which is evident in waking fresh, active and vigorous.

The fifth is related to self-control repertories, this means everything that has to do with controlling behavior, thoughts, emotions and feelings. And the sixth and final dimension is the overall health-related perceptions of illness of patients (Badia et al., 2002).

The reliability or internal consistency of the subjective well-being index is 0.9 and each dimension scored between 0.56 and 0.88 . The results of the scale range from 22 points which represents a severe discomfort and 132, which means positive well-being. The total score is calculated from dimensional scores, with categories created as such: ranging from 0 to 60 represents a serious discomfort; from 61 to 72 is a moderate malaise and from 73 to 110 is a positive welfare.

Sociodemographic data record. It is a tool built specifically for the Welfare and Psychological Health Project, carried out by the Psychology Faculty at the Pontificia Universidad Javeriana and adapted to the characteristics of the population of this investigation.

\section{Procedure}

Initially the review was conducted of the various databases to locate through medical records, patients who met the inclusion criteria for this study. Patients who met the requirements for inclusion in the study signed an informed consent that specified in their agreement to participate in research. Then, they completed: the "Questionnaire for data collection of sociodemographic data," the "Quality of Life Questionnaire SF-36 (Ware \& Sherbourne, 1992, cited by García \& Lugo, 2002) and "The psychological Well-Being Index" (Dupuy, 1984, cited by Badia, et al., 2002). Average data collection time was about forty-five minutes per patient.

Once the data was collected, the data analysis was carried out. In order to describe the characteristics of the population, a descriptive analysis was used, and also for 
the correlational analysis of the two instruments Pearson correlations were used, and Cronbach alpha was used to assess the reliability of each instrument. The results were presented in tables and bar charts and pie graphics.

\section{Results}

The sample of participants consisted of 75 women ( $93.33 \%$ female, $6.67 \%$ male). The age distribution shows an average of 27 years, with a minimum age of 27 and maximum of 76 . The ages of the participants have a central range between 45 and 61 years. Furthermore it is noted that $50 \%$ of the participants were married, followed by $18.9 \%$ being single. $36 \%$ have between 2 and 3 children, followed by $25.33 \%$ with between 4 and 5 children. Additionally it should be noted that the average age of the children ranges between 28 and 29 years. $32 \%$ had technical training at college, $25.33 \%$ have completed secondary education and $21.33 \%$ had incomplete secondary. The two occupations with the highest representation are home $(50.67 \%)$ and employees with a $33.33 \%$.

Figure 1 identifies that $30.67 \%$ of the population was diagnosed 49 months ago or more, followed by $26.67 \%$ with a diagnosis issued between 25 and 36 months ago.

Table 1 identifies the different combinations of symptoms that led participants to consult their physician and half of whom were diagnosed with thyroid cancer. This table can show that most patients noticed their condition due to the presence of a mass in the neck area. Table 1 also provides evidence that most patients received additional treatment as Iodinetherapy, the $25.3 \%$ received no additional treatment and only two persons received different treatments (Hormone therapy and psychiatric treatment).
$45 \%$ of patients showed no symptoms as a result of additional treatments, $10 \%$ reported feeling tired and decaying, while the vast majority of the remaining patients showed a combination of those with less frequent symptoms.

The $53.33 \%$ reported a history of disease, while the remaining $46.67 \%$ did not. The disease with highest reported prevalence $(8 \%)$ is hypertension; other diseases and treatments such as myomas, anemia, hemorrhoidectomy, breast cancer and diabetes, hiatal hernia, gastritis, total hysterectomy, migraines, high triglyceride and cholesterol, dizziness, varicose veins and tendonitis, osteoporosis, endometriosis, appendicitis, arthritis, kidney stones, gall bladder operation, pain in the hypochondrium, among others, are only represented by $1.3 \%$ each, and the sum of these individual values adds up to $53.33 \%$ in the previous disease report.

Figure 2 illustrates the distribution of scores for the Scale of Psychological Well-Being Index. The average of the scale is 100 points with a standard deviation of 20 points, a minimum score of 34 and maximum of 131 .

Table 2 identifies that $90 \%$ of participants were classified into the positive range of well-being, which identifies that there is a favorable trend compared to the psychological perception the participants have, while $4 \%$ reported feeling unwell and moderate only $3 \%$ is a serious malaise concerns.

We calculated the index of reliability for the 22 items of the instrument. Cronbach's alpha is 0,955 making it excellent for the Psychological Well-Being Index. As noted in Table 3, the averages of the items ranging from 4 to 5 points, except for item 1. Overall What is meaning? (During the last week) with an average of 3.52 .

Figure 1. Distribution by time of diagnosis

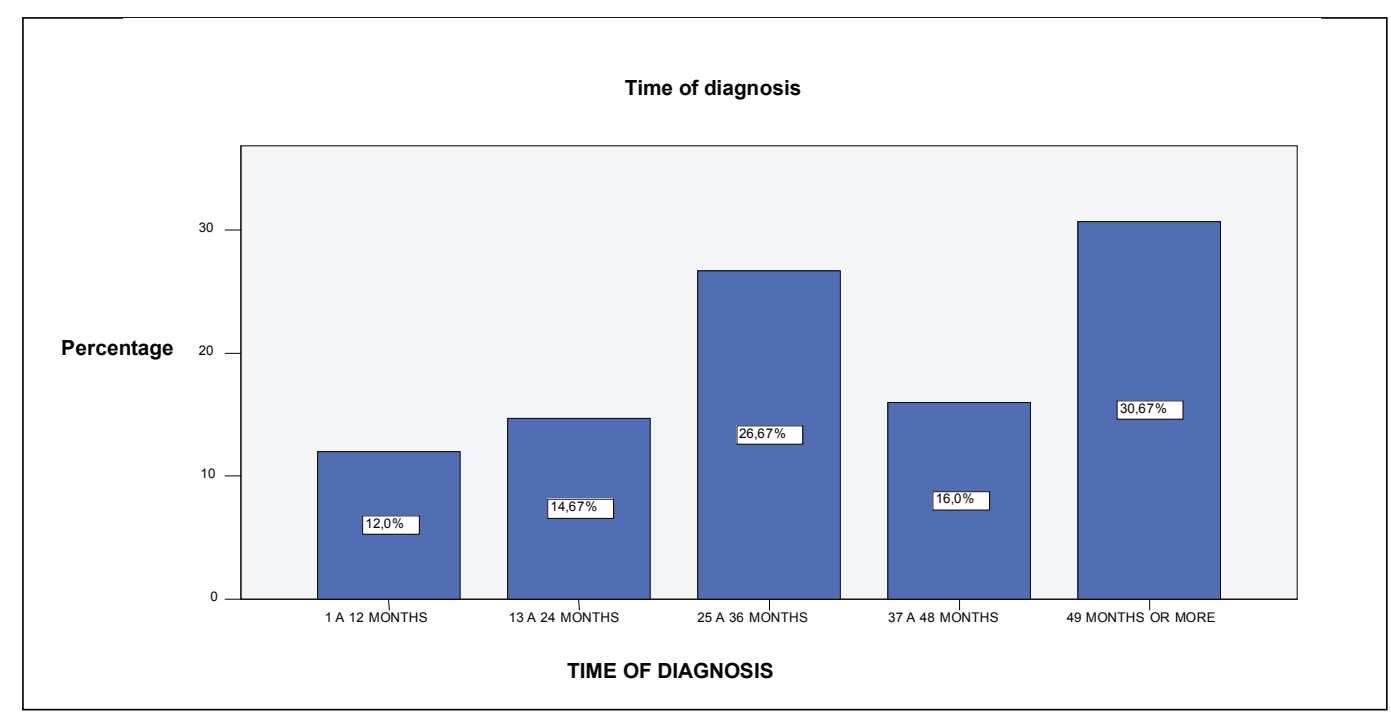


Table 1. Percentage of more representative symptoms, post-surgery and effects of treatment which participants express

\begin{tabular}{|c|c|c|c|c|c|}
\hline Symptoms & $\mathrm{N}$ & Treatment-after surgery & $\mathrm{N}$ & Treatment Effects & $\mathrm{N}$ \\
\hline Mass & $34(45.3 \%)$ & Iodinetherapy & $54(72 \%)$ & \multirow{2}{*}{$\begin{array}{l}\text { None } \\
\text { Tiredness and decay }\end{array}$} & $34(45,3 \%)$ \\
\hline None & $11(14.7 \%)$ & None & $19(25,3 \%)$ & & $8(10,7 \%)$ \\
\hline Others & $3(4,0 \%)$ & Hormonetherapy & $1(1,3 \%)$ & \multirow{2}{*}{$\begin{array}{l}\text { Decay } \\
\text { Dry skin and tiredness }\end{array}$} & $5(6,7 \%)$ \\
\hline The sixth cranial nerve palsy & $3(4,0 \%)$ & Psychiatric & $1(1,3 \%)$ & & $3(4,0 \%)$ \\
\hline Cough and mass & $2(2,7 \%)$ & & & Tiredness & $2(2,7 \%)$ \\
\hline $\begin{array}{l}\text { Weight and } \\
\text { mass gain }\end{array}$ & $2(2,7 \%)$ & & & Decay, dry skin, tiredness & $2(2,7 \%)$ \\
\hline $\begin{array}{l}\text { Coughing } \\
\text { and Pain }\end{array}$ & $2(2,7 \%)$ & & & & \\
\hline General malaise and Mass & $2(2,7 \%)$ & & & & \\
\hline
\end{tabular}

Figure 2. IBP Scale.

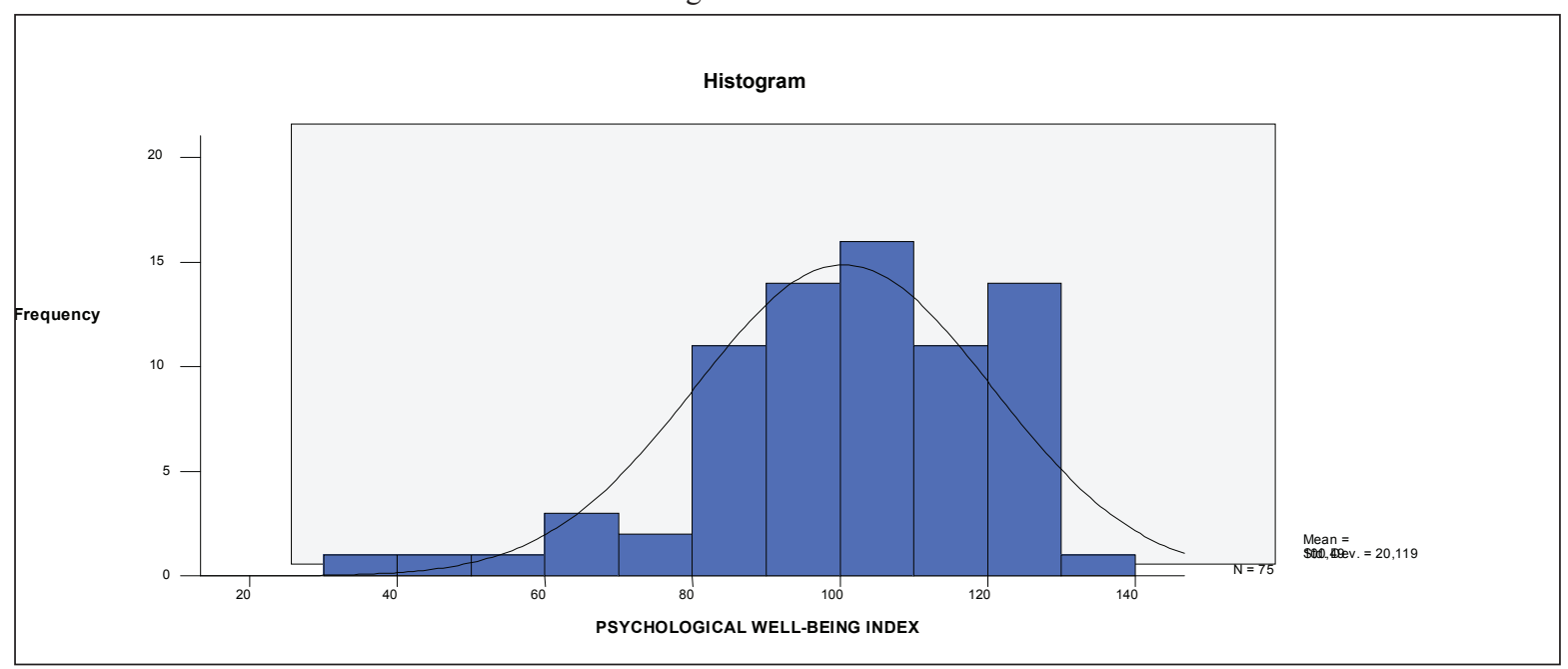

Table 2. Classification Ranges for Index of Psychological Well-Being

\begin{tabular}{lcc}
\hline Levels & Frequency & Percentage \\
\hline Severe discomfort & 3 & $4,0 \%$ \\
Moderate discomfort & 4 & $5,3 \%$ \\
Positive welfare & 68 & $90,7 \%$ \\
\hline
\end{tabular}

\section{Analysis of Health Quality of Life Questionnaire $S F-36$}

The following are the results of the analysis of the SF36 Health Questionnaire, as the framework for calculating and interpreting according to Alonso, Prieto \& Antó (1995).

The questionnaire comprises 36 items that allow for the calculation of 8 subscales which showed an excellent level of reliability of Cronbach's Alpha $(0,904)$ for the case of the 75 participants of this study.

Additionally, Table 4 presents the bivariate correlations between the subscales of the SF36 Health Questionnaire.
In this article we can identify that all correlations were calculated with the Pearson coefficient level as they are in interval level of measurement and $99 \%$ are significant since the significance levels in all cases is $(0.000)$ therefore are under $(0,01)$. Taking into account the correlation indexes mainly highlights the correlations between: 1) mental health and vitality $(.845), 2$ ) physical functioning and physical role $(.753), 3)$ vitality and physical role $(.652), 4)$ social functioning and role physical $(651), 5)$ mental health and vitality (.645), and 6) physical functioning and vitality (.635).

Table 5 presents the descriptive analysis with minimum values, maximum and average deviations for each of the 
Table 3. Descriptive Analysis of items of IBP

\begin{tabular}{|c|c|c|c|}
\hline ITEM DESCRIPTION & Average & Standard Desviation & $\mathrm{N}$ \\
\hline 1. Overall, What do you had been feeling? (During the last week) & 3,52 & 1,256 & 75 \\
\hline 2. How often you have discomfort due to an illness, discomfort or pain? & 4,11 & 1,429 & 75 \\
\hline 3. ¿Are you felt depressed? ( during the last week) & 5,21 & 920 & 75 \\
\hline $\begin{array}{l}\text { 4. ¿ Have you been able to completely dominate their behavior, thoughts, } \\
\text { emotions or feelings? }\end{array}$ & 5,08 & 1,136 & 75 \\
\hline 5. ¿Have you suffered from nerves? (During the last week) & 4,77 & 1,503 & 75 \\
\hline 6. ¿How much energy and vitality have you sense? (During the last week) & 4,31 & 1,174 & 75 \\
\hline 7. I felt sad and dejected (the last week) & 4,69 & 1,090 & 75 \\
\hline 8. Overall, ¿Have you feel on tension?, (During the last week) & 4,35 & 1,615 & 75 \\
\hline 9. Has you been satisfied and happy with your life? (During the last week) & 4,55 & 1,166 & 75 \\
\hline $\begin{array}{l}\text { 10. Has you felt well enough to do things you enjoy doing or that I had to do? } \\
\text { (During the last week) }\end{array}$ & 5,00 & 1,090 & 75 \\
\hline $\begin{array}{l}\text { 11. Have you felt so sad and discouraged or had so many problems that came } \\
\text { to wonder if there was something worthwhile? (During the last week) }\end{array}$ & 5,43 & ,989 & 75 \\
\hline 12. I am weaking up fresh and rested up (the last week) & 4,27 & 1,436 & 75 \\
\hline 13. Have you been worried or fearful for their health? (During the last week) & 4,25 & 1,396 & 75 \\
\hline $\begin{array}{l}\text { 14. Have you had any reason to wonder whether the reason or was losing } \\
\text { control over their behavior, talk, think, feel or about your memory? (During } \\
\text { the last week) }\end{array}$ & 5,39 & 1,138 & 75 \\
\hline 15. My life has been full of interesting stuff (the last week) & 4,21 & 1,328 & 75 \\
\hline $\begin{array}{l}\text { 16. Has you been active, energetic, apathetic or on the contrary, not win an- } \\
\text { ything? (During the last week) }\end{array}$ & 4,43 & 1,265 & 75 \\
\hline 17. Have you felt anxious, worried or upset? (During the last week) & 4,80 & 1,375 & 75 \\
\hline 18. I feel emotionally balanced and self-assured (the last week) & 4,91 & 1,337 & 75 \\
\hline $\begin{array}{l}\text { 19. Have you found a happy, relaxed or, conversely, nervous, tense or angry? } \\
\text { (During the last week) }\end{array}$ & 4,33 & 1,234 & 75 \\
\hline 20. I was happy (the last week) & 4,17 & 1,329 & 75 \\
\hline 21. I felt tired (during the last week) & 4,21 & 1,222 & 75 \\
\hline 22. has you been believed to be in tension or stress? (During the last week) & 4,51 & 1,369 & 75 \\
\hline
\end{tabular}

8 subscales and the two scales were calculated using standard physical and mental components of the SF36 Health Questionnaire. It is worth noting that all subscales had maximum values of (100) points and only the subscales of physical role and emotional role had minimum values $(0)$ points. In the analysis of the mean subscale score was higher physical functioning $(X=80.46)$ and the lowest average life $(X=63.26)$. On the other hand the last two rows of the table presents the standard scale for the physical and mental, in this sense with values ranging between 25 and 60 points for the physical component and between 17 and 62 points for the mental component, the additional component presents a physical average $(X=48.22)$ slightly higher than in the mental component $(X=45.19)$.

Table 6 presents the correlations between psychological well-being index and the standard scales of the SF36 health questionnaire. These were calculated using the Pearson coefficient as the measurements are in interval level. At first it appears that the three correlations are significant at $99 \%$ as their level of significance is in all cases $(0,000)$ less than $(0,01)$ and also are positive, which indicates that there are significant correlations between direct and proportional the Index of Psychological Well-being and the physical and mental health questionnaire SF36, mainly emphasizing the correlation between the PPI and the Mental Component (815).

Next, scatter diagrams are presented, in which the trend in direct proportion to each of the three correlations analyzed in Table 6 with Figures 3,4 and 5 are observed. Each of the diagrams shows how people who have high values obtained in any one of the scales tend to have equally high values in other scales and vice versa.

Finally, Table 7 presents correlations between the time of diagnosis, measured in ordinal scale scores, and Psychological Well-Being Index, the Physical Component 
Figure 3. Scattering diagram for the correlation between the physical component of the Health Questionnaire SF36 and the Psychological Well-Being Index.

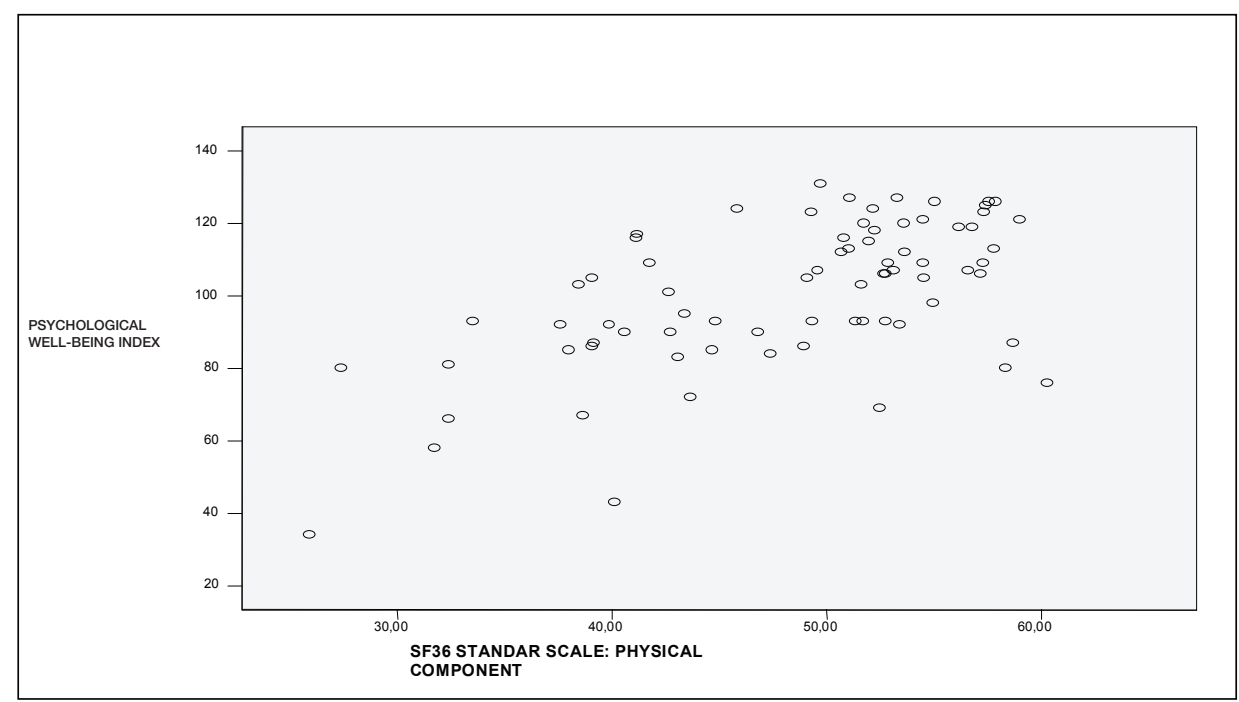

Figure 4. Scattering diagram for the correlation between the Mental Component of the SF36 Health Questionnaire and the Index of Psychological Well-Being.

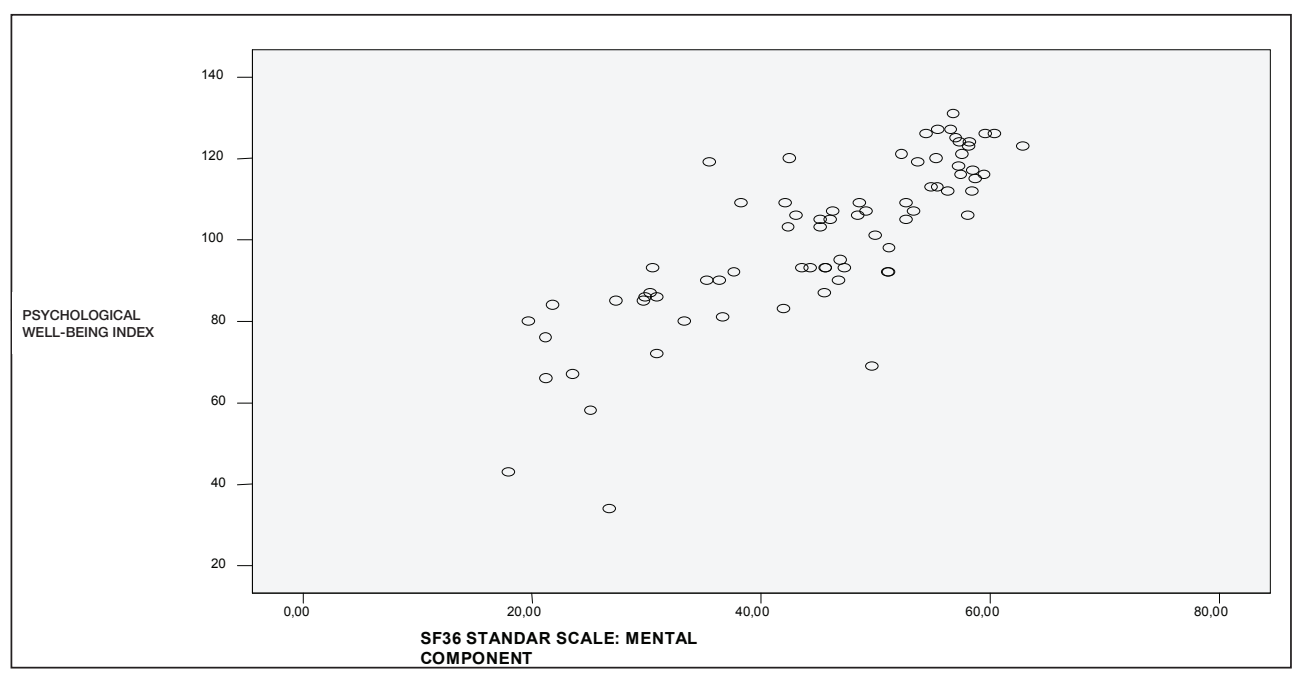

and Mental Component of the SF36 Health Questionnaire. Correlations were calculated using Spearman's coefficient, as it has an ordinal variable versus other variables that are interval-leveled. From the results presented by the table, it appears that the strongest correlation is between the PPI and the time of diagnosis, being significant at $99 \%$ but with a lower magnitude (.311) which indicates that the higher the time of diagnosis there is a greater tendency to higher levels of psychological well-being. In the second instance there was also a significant positive correlation and $95 \%$ with a lower magnitude between the time of diagnosis and the physical component of the SF36 (253). Furthermore, the correlation between time of diagnosis and the Mental Component of the SF36 was not significant.

\section{Discussion}

Advances in health in recent decades and the research conducted in the clinical-epidemiological area have clarified the link between health and a range of factors beyond the biological aspects, resulting in a number of categories that have contributed to the psychosocial development of studies on the psychological well-being and quality of life.

Taking into account the complexity of these concepts, their interrelationships and influence on human development, it is important to understand their use as factors to assess the adjustment to different situations faced by people of their life. 
Table 4. Correlations between the 8 subscales of Questionnaire SF36

\begin{tabular}{|c|c|c|c|c|c|c|c|c|}
\hline $\begin{array}{r}\text { PEARSON'S } \\
\text { COEF }\end{array}$ & $\begin{array}{l}\text { CORRELATIONS } \\
\text { FICIENTS }\end{array}$ & $\begin{array}{c}\text { SF-36 } \\
\text { PHYSICAL } \\
\text { FUNCTION } \\
(0-100) \\
\end{array}$ & $\begin{array}{c}\text { SF-36 } \\
\text { PHYSICAL } \\
\text { ROL } \\
(0-100) \\
\end{array}$ & $\begin{array}{c}\text { SF-36 } \\
\text { CORPORAL } \\
\text { PAIN } \\
(0-100) \\
\end{array}$ & $\begin{array}{c}\text { SF-36 } \\
\text { GENERAL } \\
\text { HEALTH } \\
(0-100) \\
\end{array}$ & $\begin{array}{l}\text { SF-36 } \\
\text { VITALITY } \\
(0-100)\end{array}$ & $\begin{array}{c}\text { SF-36 } \\
\text { SOCIAL } \\
\text { FUNCTIONING } \\
(0-100) \\
\end{array}$ & $\begin{array}{c}\text { SF-36 } \\
\text { MENTAL } \\
\text { HEALTH } \\
(0-100) \\
\end{array}$ \\
\hline $\begin{array}{l}\text { SF-36 } \\
\text { PHYSICAL } \\
\text { FUNCTION } \\
(0-100)\end{array}$ & $\begin{array}{l}\text { Pearson Correlation } \\
\text { Sig. (bilateral) }\end{array}$ & & & & & & & \\
\hline SF-36 & Pearson Correlation &, $753(* *)$ & & & & & & \\
\hline $\begin{array}{l}\text { PHYSICAL ROL } \\
(0-100)\end{array}$ & Sig. (bilateral) & ,000 & & & & & & \\
\hline SF-36 & Pearson Correlation &, $417(* *)$ &, $578(* *)$ & & & & & \\
\hline $\begin{array}{l}\text { CORPORAL } \\
\text { PAIN }(0-100)\end{array}$ & Sig. (bilateral) &, 000 &, 000 & & & & & \\
\hline SF-36 & Pearson Correlation &, $604(* *)$ &, $464(* *)$ &, $434(* *)$ & & & & \\
\hline $\begin{array}{l}\text { GENERAL } \\
\text { HEALTH }(0-100)\end{array}$ & Sig. (bilateral) &, 000 &, 000 & ,000 & & & & \\
\hline SF-36 & Pearson Correlation &, $635(* *)$ &, $652(* *)$ &, $600(* *)$ &, $645(* *)$ & & & \\
\hline $\begin{array}{l}\text { VITALITY } \\
(0-100)\end{array}$ & Sig. (bilateral) & 000 &, 000 &, 000 &, 000 & & & \\
\hline SF-36 SOCIAL & Pearson Correlation &, $476(* *)$ &, $523(* *)$ &, $651(* *)$ &, $347(* *)$ &, $573(* *)$ & & \\
\hline $\begin{array}{l}\text { FUNCTIONING } \\
(0-100)\end{array}$ & Sig. (bilateral) & 000 &, 000 &, 000 &, 002 &, 000 & & \\
\hline \multirow{2}{*}{$\begin{array}{l}\text { SF-36 MENTAL } \\
\text { HEALTH }(0-100)\end{array}$} & Pearson Correlation &, $587(* *)$ &, $611(* *)$ &, $531(* *)$ &, $609(* *)$ &, $845(* *)$ &, $603(* *)$ & \\
\hline & Sig. (bilateral) &, 000 &, 000 &, 000 & ,000 &, 000 &, 000 & \\
\hline
\end{tabular}

$\overline{* *}$ Significant correlation as 0,01 level (bilateral).

Table 5. Descriptive analysis for the subscales and scales of Standard SF36

\begin{tabular}{|c|c|c|c|c|c|}
\hline Subescalas y Escalas & $\mathrm{N}$ & Mínimun & Maximun & Average & $\begin{array}{c}\text { Typical } \\
\text { Desviation }\end{array}$ \\
\hline SF-36 PHYSICAL FUNCTION (0-100) & 75 & 5,00 & 100,00 & 80,4667 & 24,71696 \\
\hline SF-36 PHYSICAL ROL (0-100) & 75 & 00 & 100,00 & 67,0000 & 41,74407 \\
\hline SF-36 CORPORAL PAIN (0-100) & 75 & 21,00 & 100,00 & 71,8667 & 25,14785 \\
\hline SF-36 GENERAL HEALTH (0-100) & 75 & 30,00 & 100,00 & 65,9333 & 19,08893 \\
\hline SF-36 VITALITY $(0-100)$ & 75 & 5,00 & 100,00 & 63,2667 & 23,32921 \\
\hline SF-36 SOCIAL FUNCTIONING (0-100) & 75 & 12,50 & 100,00 & 76,8333 & 29,32902 \\
\hline SF-36 EMOTIONAL ROL (0-100) & 75 & 00 & 100,00 & 72,0000 & 41,02296 \\
\hline SF-36 MENTAL HEALTH (0-100) & 75 & 16,00 & 100,00 & 67,4667 & 21,99099 \\
\hline $\begin{array}{l}\text { SF36 STANDAR SCALE: } \\
\text { PHYSICAL COMPONENT }\end{array}$ & 75 & 25,90 & 60,27 & 48,2273 & 8,16159 \\
\hline $\begin{array}{l}\text { SF36 STANDAR SCALE: } \\
\text { MENTAL COMPONENT }\end{array}$ & 75 & 17,96 & 62,87 & 45,1905 & 12,00712 \\
\hline Valid $\mathrm{N}$ ( according to list) & 75 & & & & \\
\hline
\end{tabular}


Figure 5. Scattering diagram for the correlation between the Mental Component of the SF36 Health Questionnaire and the physical component of the SF36

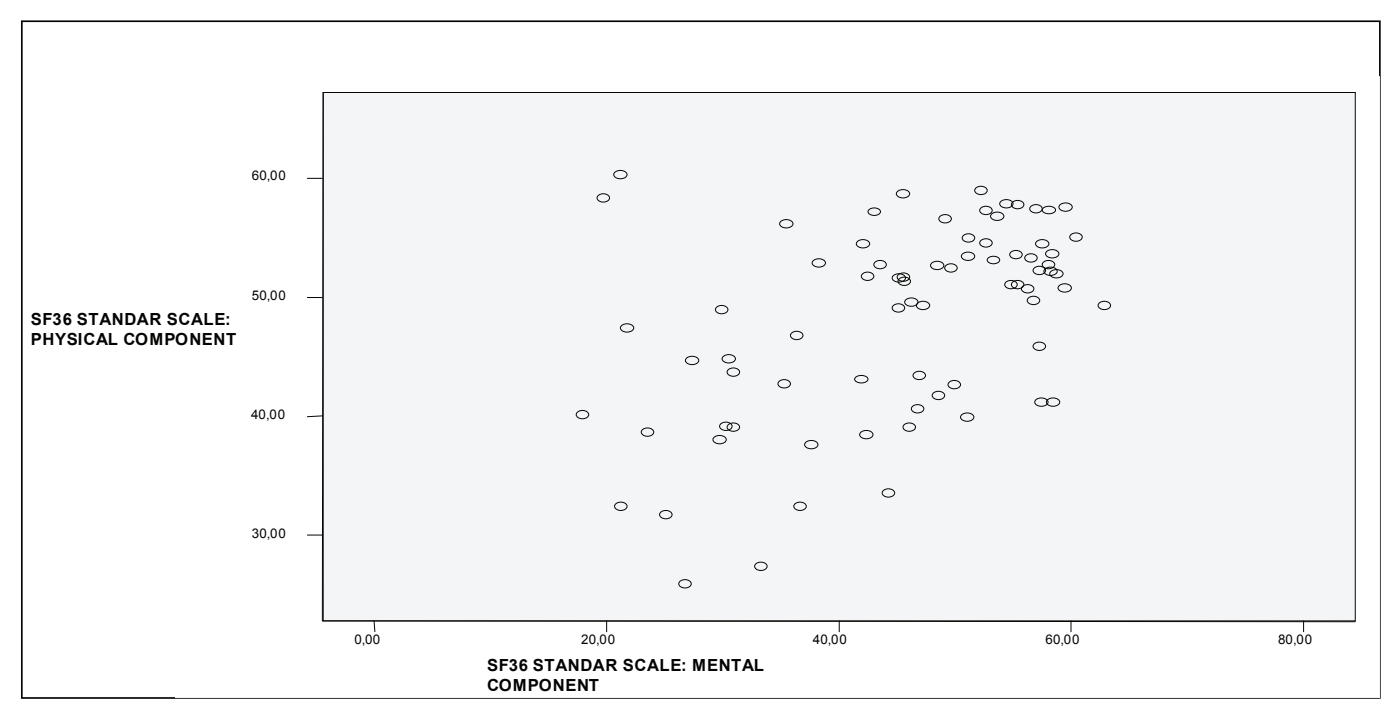

Table 6. Pearson's correlations between Psychological Well-Being Index and Standard Scales of Health Questionnaire SF36

\begin{tabular}{llcc}
\hline \multicolumn{1}{c}{ PEARSON'S CORRELATIONS COEFFICIENTS } & $\begin{array}{c}\text { PSYCHOLOGICAL } \\
\text { WELL-BEING INDEX }\end{array}$ & $\begin{array}{c}\text { SF36 STANDAR SCALE: } \\
\text { PHYSICAL COMPONENT }\end{array}$ & $\begin{array}{c}\text { SF36 ESTANDAR SCALE: } \\
\text { MENTAL COMPONENT }\end{array}$ \\
\hline PSYCHOLOGICAL & Pearson's Correlation & & \\
WELL-BEING INDEX & Sig. (bilateral) & & \\
& $\mathrm{N}$ &, $591\left(^{* *}\right)$ & \\
SF36 STANDAR SCALE: & Pearson's Correlation &, 000 & \\
PHYSICAL COMPONENT & Sig. (bilateral) & 75 &, $473(* *)$ \\
& $\mathrm{N}$ &, 000 \\
SF36 STANDAR SCALE: & Pearson's Correlation &, $815(* *)$ & 75 \\
MENTAL COMPONENT & Sig. (bilateral) &, 000 & 75 \\
& $\mathrm{~N}$ & 75 & \\
\hline
\end{tabular}

$\overline{* *}$ Significant correlation as 0,01 level (bilateral).

One of the situations that test the resources available to individuals is the change of health status, understood as a determinant of the quality of life, and being one of the components involved in the establishment of psychological well-being.

Beyond the health goal, however (physical impairment or medical conditions in general) is the subjective interpretation made of it, which affects the emotional adjustment of individuals. As emphasized by Diener et al., (2003), it is the perception of the individual with regard to the situation that generates impact on health.

Given the "myth" and fear that arise from cancers, due to their high levels of mortality, there have been technological advances that increase the likelihood that a person with such a condition can lead a normal and appropriate life; this progress has achieved either the cure or the handling of the disease, by means of early detection. This facilitates identification of cancer and allows for the projection of the most appropriate treatment.

Measures such as those mentioned above, have led a group of survivors who represent a very important study population for different areas of knowledge. Thus, for example social sciences have made approaches to assess areas such as quality of life, psychological well-being and spirituality, among others (Tomich \& Helgeson, 2002).

In this study, according to the above considerations, we administered the Psychological Well-Being Index (Dupuy et al., 1984) and the Health Quality of Life Questionnaire SF-36 (Ware \& Sherbourne, 1992) to 75 cancer patients with thyroidectomy who received treatment in order to access the group of survivors of this disease and have a specific knowledge of the variables that influence the quality of life and psychological well-being. 
Table 7. Pearson's correlations between diagnosis time, Psychological Well-Being Index and Standard Scales of Health Questionnaire SF36

\begin{tabular}{|c|c|c|}
\hline PEARSON'S CORRELATIONS COEFFICIENTS & & DIAGNÓSIS TIME \\
\hline \multirow{3}{*}{ DIAGNÓSIS TIME } & Pearson's Correlation & 1,000 \\
\hline & Sig. (bilateral) & \\
\hline & $\mathrm{N}$ & 75 \\
\hline \multirow{3}{*}{ PSYCHOLOGICAL WELL-BEING INDEX } & Pearson's Correlation &, $311(* *)$ \\
\hline & Sig. (bilateral) &, 007 \\
\hline & $\mathrm{N}$ & 75 \\
\hline \multirow{3}{*}{ SF36 STANDAR SCALE: PHYSICAL COMPONENT } & Pearson's Correlation &, $253(*)$ \\
\hline & Sig. (bilateral) & 029 \\
\hline & $\mathrm{N}$ & 75 \\
\hline \multirow{3}{*}{ SF36 STANDAR SCALE: MENTAL COMPONENT } & Pearson's Correlation & 219 \\
\hline & Sig. (bilateral) & 059 \\
\hline & $\mathrm{N}$ & 75 \\
\hline
\end{tabular}

** Significant correlation as 0,01 level (bilateral).

* Significant correlation as 0,05 level (bilateral).

An analysis was done to corroborate what is mentioned in the investigations in the introduction, regarding the prevalence of such diseases.

It was also found that most patients identified a mass in the neck as the first symptom, which led them to consult with the head and neck specialist, who, in addition to carrying out the surgical procedure, provided iodinetherapy treatment to $70.7 \%$ of patients.

In this regard, $55 \%$ of patients claimed to have presented with malaise, fatigue and dryness as the main symptoms of thyroid cancer and its treatments, whereas $45 \%$ of people said that these treatments did not generate any significant side effects.

The findings bring about considerations in defining psychological well-being as described by Garcia \& Viniegra-González (2000) who consider it to be a subjective, experiential and changing construct that expresses the positive mood and the constructive thinking of human beings about themselves in the present moment, as well as what was expressed by Ballesteros et al., (2003) who argue that "human beings face problems at different times in life and psychological well-being can therefore change over time due not only to the intensity of such problems, but to their length" (Ballesteros, et al., 2003).

Likewise, psychological well-being includes the analysis of the assessment of people over their own lives, present and historical, including emotional reactions, mood, and judgments about satisfaction with life in areas such as moral, marriage, health and work, among others. (Diener et al., 2003).

This subjective assessment is closely related to conditions associated with health status, since, although there are objective indicators (mostly biological) of a health situation, subjective indicators are as important as them, as manifested people's self-reports.

Stressing the value self-reports, the Psychological Wellbeing Index (PPI) by Dupuy et al., (1984) was applied, which assessed the valuation of health status in relation to the perception of patients and is involved in their daily life in order to assess subjective feelings of well-being and psychological distress (Badia, et al., 2002).

The descriptive analysis of the Psychological WellBeing Index (Dupuy et al., 1984) found that $90 \%$ of patients had a high rate of positive well-being. However, $4 \%$ of participants presented severe malaise, and $5.3 \%$, a moderate well-being. In this regard, findings by Ballesteros \& Caycedo (2002) are consistent with the results obtained, which suggest that "feeling good involves more chances of action, and there is a higher chance of feeling good and enjoying life when there is no need to do unpleasant things". As most patients who were evaluated had had surgery more than a year before, it is understandable that "unpleasant things" directly related to the disease had become less important or intermingled with everyday life, making them more tolerable and predictable, and therefore easier to deal with.

Yet, it is also important to note that "it is possible to have a good life despite illness and adverse circumstances, since there is a chance to change, up to some point, the unfavorable conditions associated to them" (Ballesteros \& Caycedo, 2002), or to assess them differently, in such a way that their repercussion on emotional status, and therefore, on people's behavior, will be also different. 
Therefore, when carrying out the IBP analysis by category, most participants report feeling good, and the rest lies within the central ranges, with only a small percentage in critical or negative conditions in each dimension. For example, with regards to anxiety, $2,7 \%$ of patients reports feeling very anxious, while about $40 \%$ of the sample reports no feelings of anxiety or tension related to their health condition.

In this line, Klee, King, Machin \& Hansen (2000) indicate that there are variables among people with cancer which affect their reactions towards the disease and, therefore, their perception of well-being at a certain point in time, such as the different stages of disease, the presence of symptoms and the level of alteration of individual functioning, besides the fact of having experienced previous illness, the moment in life where the disease appears, the flexibility of the individual to cope with the situation and the consciousness, and the impact of the event on the family or primary social group.

The same thing occurs in the second category, which deals with depression. $33 \%$ of the participants report no feelings of depression, and being sad in a few occasions. $4 \%$ report high feelings of depression.

Despite treatment advances, early detection techniques, cure rates and increases in disease-free time, cancer is still being associated to mortality, which involves significant psychological repercussions for some people.

Prevalence rates for psychological and psychiatric problems in this group of patients vary from 1 to $49 \%$. It has been said that over $24 \%$ of cancer patients, on average, experience depression symptoms, and more than half experiences symptoms qualifying for a clinical diagnosis of depression (Manne \& Schnoll, 2001).

The category of positive mood showed how $4 \%$ reported having a negative mood, in contrast to $25 \%$ of people who said they felt a very positive mood; in terms of vitality, it can be seen that $2 \%$ of patients expressed feeling totally dejected, with low energy and vitality, whereas $19.3 \%$ reported feeling very full of vitality. A small percentage is distributed in different values with a tendency to feel vitality rather than apathy and reluctance.

This study shows support for proposals made by Evans, Burnell, Hopwood \& Howell (1993), who point out that there are characteristics of individuals who allow them to access more appropriate coping mechanisms, and thus have appropriate management of levels of psychological well-being, such as patience, perseverance and energy with regard to their health condition; these are patients who are friendly, avoid ambiguity, are autonomous, independent and self sufficient. These characteristics are related to the fighting spirit stated by Greer (1988, cited by Evans, et al., 1993) (optimistic attitude together with seeking as much information as possible in order to fight it) and the style of "positive / confrontational coping," concepts associated to psychological well-being and longevity in cancer patients (Evans et al., 1993).

The fifth category is related to self-control, and the same distribution is held in it, even though it leans a bit to the total perception of self-control with a share of $50.6 \%$ and only $2.2 \%$ reporting to have no control over themselves.

In this regard, behavior analysis states that self-control is choosing a better, but long-term consequence, over an immediate one. This definition allows for the presentation of this process in terms of the behaviors emitted by the individual in the environment, and it is applicable in different contexts. Self-control is therefore a key to Psychological well-being when taking into account that, as previously mentioned, it is possible to moderate the positive reinforcement contingencies in order to feel positive well-being in adverse circumstances, despite the inherent difficulties of this process (Ballesteros \& Caycedo, 2002).

Finally, regarding the perception of general health, patients report finding themselves more in the middle rather than at the extremes, and said that despite feeling good health, they could feel better, and only $4 \%$ said they felt bad in this aspect. This may be because although the treatment is working well, the chances of experiencing again some pathology related to cancer or have a relapse are always present, in addition to various other diseases that may occur more frequently in certain age groups.

It is important to emphasize those items that showed the greater well-being, which were specifically related to the categories of depression, self-control and general health. On the contrary, the item with the lowest score was number 1 , which refers to the positive mood. However, it does not reflect a trend towards either of the extremes.

From the descriptive and correlational analysis, the degree of reliability of this instrument reveals itself as very high. As for the correlational analysis, it is important to mention that all the correlations were high and ranging from 0.449 to 0.844 , which shows a high internal consistency in the instrument.

Based on the results and their analysis, it is possible to show how the psychological well-being is the result of the continuous interaction of the individual with his or her environment. And therefore, being an integral part of a behavioral process, well-being could be considered as a spatiotemporal event maintained by all the contextual variables, considering the same individual as the builder of much of his or her reinforcement contingencies. (Ballesteros \& Caycedo, 2002).

The health status of individuals, therefore, prove to be a key part in their reinforcement contingencies, but these health conditions do not only depend on the objective aspect that goes along with them, but they are more linked to individual construction made of them; hence, the continuous process of exchange between the individual and 
the context is what changes the individual's perception of psychological well-being.

Another factor or dimension that is closely related to psychological well-being is the quality of life, defined by López \& Torres (2001) as "the ability of patients to manage and lead their lives according to how they evaluate their functioning". Similarly, Diener (1984, cited by RodríguezMarín, 1998) defines it as a subjective view of the extent to which happiness, satisfaction, or a sense of personal well-being have been achieved, but also the subjective judgment has been considered to be closely related to certain objective indicators: biological, psychological, behavioral and social factors.

In global terms the quality of life represents conditions related to public health, but when it comes to people suffering from illness or undergoing treatment, indicators of dysfunction and disability related to the process in which the individual is are used; in this sense, reference to the functional status and the psychological and social function is made (Rodríguez- Marín, 1998). In order to access these dimensions, the Health Quality of Life Questionnaire SF-36 designed by Ware \& Sherbourne (1992) was used, as it is a comprehensive tool when evaluating the functional status (García \& Lugo, 2002).

When it comes to quality of life in patients who received thyroidectomy as a treatment for cancer, in relation to the above, they are asked about their functional status, i.e. the extent to which they adapt to the presence of painful symptoms or disabilities, how they handle themselves psychologically in the cognitive, emotional and behavioral levels, and what their level of social adaptation and employment is, all rated on a global basis by the patient, since the diagnosis of cancer changes the way the person sees himself or herself and sees their life, profoundly affecting their self concept.

In the descriptive analysis with minimum values, maximum and average deviations for each of the eight subscales and two scales calculated using standard components of physical and mental health questionnaire SF-36, it was found that all subscales showed maximum values of (100) points and only the subscales of physical role and emotional role of minimum values $(0)$ points. In the mean analysis the higher subscale score was physical functioning $(X=80.46)$ and the lowest average life $(X=63.26)$.

Specifically in the sub-scale of physical functioning, it was shown that the average is 80.4667 , which indicates that most patients reported having no limitation for physical activity, such as self-care, walking, climbing stairs, bow, take or carry weights. The lowest score was 5.00 which shows that a minimum percentage of the population says to be very limited due to their illness and the maximum physical effort that shows that patients are not limited in any way was 100.0 .

In relation to the physical role and extent to which physical health interferes with work and other daily activities including performance lower than desired, the average was 67.00 indicating that the interference of the disease on the daily life of patients is not very high. It was also found that patients scored a minimum of 0.0 which shows problems for their daily activities and a maximum score of 100.0, indicating that the thyroid cancer and treatment have not limited these activities.

The previous findings are equally true for bodily pain, which had an average of 71.8667. This figure indicates that most patients are not affected by physical pain that compromises their performance or their daily activities. It is important to notice that the minimum score was 21.0 , which indicates that while some patients have pain and are affected by it, it does not restrict them completely, in contrast to a maximum score of 100.0 which states that participants report to have not been affected by pain, either because it has not been felt or because its intensity was too low.

Mental function is a construct related to the feeling, thinking and acting of human beings, defined by its subjective and experiential nature. As cancer patients deal with high levels of stress and uncertainty because of their illness and recovery, areas such as the emotional role, mental health and vitality can be affected (Goepper \& Hammond, 1977).

With regard to mental health, the average score of the population in this area is 67.4667 which shows that most patients are well in terms of their psychological functioning. As for the emotional role, an average of 72.0 was discovered, which means that emotional problems related to their illness will not interfere with work or other daily activities, either because they are scarce or because they have some coping skills that enable them to cope with different situations in a positive way.

Since most of the patients were evaluated after more than a year since surgery, it is possible to state, as pointed out by Ballesteros \& Caycedo (2002), how they have been able, from the surgery up to this point, to identify the effects of their behavior on their physiological functions, and similarly to identify possibilities of action against facts they apparently had no control over, which enabled them to reduce discomfort, to increase the balance of the body, and to positively affect the psychological well-being; decisive factors for the management of the disease.

Now, in terms of vitality, it can be seen that the average was 63.2667 , a figure that is above 50 and shows that a majority of patients report feeling more energy and vitality during most of the time.

The third dimension is social functioning, which is related to the interactions among family, friends, community and work, i.e., social adjustment of the individual, and is manifested in patients as a dysfunction resulting from functional limitations due to pain, fatigue or fear of the diagnosis, treatment and its consequences. 
Regarding this aspect, it is important to note that the average was 76.8333 , which means that, on average. patients reported that problems of physical and emotional health will not interfere with their normal social activities.

Finally, we assessed the general perception of health through six items, finding an average of 65.9333 which indicates that participants have a positive perception regarding their health currently, towards the future and on resistance to disease.

Moreover, with regard to the correlational analysis of the Quality of Life Questionnaire SF-36, it was evident from the context of calculation and interpretation of Alonso et al., (1995), that its reliability estimated by coefficient through Cronbach's alpha was high $(0,904)$ and the interscale correlations evaluated using Pearson's coefficient, ranged from 0,396 to 0,760 , the minimum for the category of general health and maximum physical role. This shows that the instrument has a high degree of internal consistency between the central components of the SF36 Health Questionnaire, showing how the correlations are in all cases positive and high.

Based on the analysis of the instruments, a correlational study by means of Pearson coefficient was carried out between Psychological Well-Being Index and the standard scales of Health Quality of Life Questionnaire SF-36, to respond to the overarching research objective underpinning this article, which was to analyze the relationship between quality of life and psychological well-being of patients who had had surgery and other treatments for thyroid cancer.

Based on the approaches of interbehavioral psychology, which presumes an equivalence between psychological well-being and the functional psychological dimension of quality of life, the multidimensional level of the concept of quality of life should be acknowledged, and thus the same level of psychological well-being, (Carpio, Pacheco, Flores \& Canales, 2000, cited by \& Ballesteros \& Caycedo, 2002) found that the correlations are positive and significant at $99 \%$, mainly by emphasizing the correlation between the PPI and the Mental Component $(0,815)$, meaning that both quality of life and psychological well-being of patients are affected to the same extent by a disease such as thyroid cancer, but is also observed that as time passes after surgery, the degree of adaptation is greater and therefore these dimensions also improve.

In this sense, it is noted that the strongest correlation is between the PPI and the time of diagnosis, $99 \%$ to be significant but with a lower magnitude $(0,311)$ which indicates that the higher the time of diagnosis, the greater tendency to higher levels of psychological well-being. In the second instance there was also a significant positive correlation and $95 \%$ with a lower magnitude between the time of diagnosis and the physical component of the SF36 (0253). Furthermore, the correlation between time of diagnosis and the Mental Component of the SF36 was not significant.
Compared with previous results, it is important to note that the variation in quality of life and psychological wellbeing of cancer patients is related to the vision they have of the world of the disease because they can assume the situation as traumatic and involving management of both diagnosis and treatment, according to a re-alignment and adaptation of the experience that allows a certaing degree of control over events that occur (Tomich \& Helgeson, 2002).

In conclusion, it is important to consider that besides the pre-conceptions and prejudices about cancer, another factor involving and affecting quality of life and psychological well-being of patients is the treatment and its implications, because its complexity affects patients and the context they operate and interact in. However, over time, patients use and create new resources in order to have greater predictability and control, which enable them to face their health problems in a different way, in order to restore balance and continue their lives while increasing the levels of quality life and psychological well-being.

Consistent with this, prediction and control are essential parts of psychology as a science of behavior, and they are defined as behavioral processes that allow for the modification of behavior in relation to the environment and behavior itself, through contextual signals that permit the individual to effectively predict and control in order to avoid a negative consequence, and to optimize available resources, reorganizing behavior or environmental and contextual events (Ballesteros \& Caycedo, 2002).

In the particular case of cancer patients, the ability to feel control over their psychological well-being is an important factor in the general quality of life. From this, when coping strategies are used effectively, they will improve the perception of health status (Diener, et al., 2003) and thus contribute positively to changing levels of wellness.

This allows us to understand why, over the long term, various studies have found that measurements of psychological well-being and quality of life in cancer patients are not far away from those of healthy populations, because both groups reported high levels (Van der Zee et al., 1996).

Finally, according to the results presented in this investigation, one of the major goals of behavior analysis when it comes to psychological well-being and quality of life, is to design programs aimed at preventing risks and promoting well-being, to achieve a high impact on society, thus reducing costs (in terms of time, human resource, financial and social) for higher profit and to facilitate the achievement of a better quality of life (Ballesteros \& Caycedo, 2002). Specifically in patients with thyroid cancer, it would be possible to achieve this by means of psychological support and monitoring in the process of diagnosis and treatment during the first year after surgery.

The above in order to be able to access the contingency relationships in the patient's life, so as to establish 
new functional relationships between their behavior and their consequences, allowing for greater predictability and control over their behavior through flexible rules and consistent with the different situations that arise due to their condition.

It is important that during the first year after surgery, self-control behaviors are reinforced, because endocrine disorders alter the emotional responses of the individual (Santolaya Ochando \& Novoa-Gómez, 2009). Ensuring that a reinforcement program is applied will become an incentive to behavior directed to medium and long term goals, over the securing of immediate reinforcements.

\section{Referencias}

Alonso, J., Prieto, L., \& Antó, J. (1995). La versión española del SF-36 Health Survey (Cuestionario de Salud SF-36): un instrumento para la medida de los resultados clínicos. Medicina Clínica, 104, 771-776.

Badia, X., Salamero, M., \& Alonso, J. (2002). La Medida De La Salud: Guía de Escalas de Medición en Españo. Barcelona:Fundación Lilly.

Ballesteros de Valderrama, B. P., Botero, C., Caycedo, C., Gutiérrez, M., Hermida, G., Medina, A., Montaña, P., y Otero, M. (2003). Revisión del concepto de Bienestar Psicológico. Facultad de Psicología. Pontificia Universidad Javeriana. Documento inédito

Ballesteros, B., \& Caycedo, C. (2002). El bienestar psicológico en el marco del análisis del comportamiento. Facultad de Psicología. Pontificia Universidad Javierana. Documento inédito.

Barreda, P. (2005). Trastorno de la tiroides: un mal encubierto. Recuperado en febrero 16, 2008, de: http://www.pediatraldia.cl/pb/tiroides.htm.

Carpio, C., Pacheco, V., Flores, C., \& Canales, C. (2000). Calidad de Vida: un análisis de su dimensión psicológica. Revista Sonorense de psicología, 14, 3-15.

Diener, E., Oishi, S., \& Lucas R. E. (2003). Personality, Culture, and Subjective Well-Being: Emotional and Cognitive Evaluations of Life. Annual Review of Psychology, 54, 403-425.

Evans, G., Burnell, L., Hopwood, P., \& Howell, A. (1993). Perception of risk in women with a family history of breast cancer. British Journal of Cancer, 67,612-614.

Garavito, L. (2001). Calidad de vida y toma de decisiones médicas. Tesis de especialidad en bioética. Pontificia Universidad Javeriana. Documento Inédito.

García, H., \& Lugo, H. (2002). Adaptación cultural y fiabilidad del instrumento de calidad de vida SF36 en instituciones de Medellín. Tesis de Maestría, Medellín, Facultad Nacional de Salud Pública.

García-Viniegras, C., \& González, I. (2000). La categoría bienestar psicológico, su relación con otras categorías sociales, Revista Cubana de Medicina Integral, 16, 586-592.

Goepp, C. \& Hammond, W. (1977). Terapia de Apoyo del Paciente Canceroso. Buenos Aires: Médica Panamericana.

Gómez, V., Villegas de Posada, C., Barrera, F., \& Cruz, J.E. (2007). Factores predictores de bienestar subjetivo en una muestra colombiana. Revista Latinoamericana de Psicología, 39, 311-325.

Grau, J. \& Pörtero, D (1987). Perspectivas del Estudio del Cuadro Interno de las Enfermedades. En Memorias del Congreso Colombiano de Psicología Clínica. Facultad de Psicología de la Fundación Universitaria de Manizales, Colombia.

Instituto Nacional de Cáncer de Estados Unidos. Recuperado en Octubre 30, 2007 disponible en http://www.cancer.gov.
Klee, M., King, M., Machin, D., \& Hansen, H. (2000). Modelo clínico de evaluación de la calidad de vida de los pacientes oncológicos tratados con quimioterapia. Annals of Oncology, 9, 293-301.

López, M., \& Torres, G. (2001). Estudios sobre calidad de vida en pacientes con cáncer en tratamiento de quimioterapia. Tesis de maestría, Pontificia Universidad Javeriana.

Malagón, G., Galán, R., \& Potón, G. (1999). Garantía de calidad en salud. Bogotá: Médica Panamericana.

Manne, S., \& Schnoll, R. (2001). Measuring cancer patient's psychological distress and well-being: A factor analytic assessment of the mental health inventory, Psychological Assessment, 13, 99-109.

Novoa, M. M., Cruz Walteros, C., Rojas Serrano, L., y Wilde Winz, K. (2003). Efectos secundarios de los tratamientos de cáncer de próstata localizado, calidad de vida y ajuste marital. Universitas Psychologica, $2,169-186$

Novoa, M. (2004) Pertinencia de las interacciones entre la ciencia médica y la psicología. En: Oblitas G. L. (edts.). Manual de la psicología clínica $y$ de la salud hospitalaria. Recuperado en marzo 11, 2008 disponible en www.psicologiacientifica.com

Novoa-Gómez, M. M., Ballesteros, B. P. (2006). The role of the psychologist in an intensive care unit. Universitas Psychologica, 5, 599-613

Novoa-Gómez, M. M., Moreno, I. S., Garcia, M. P., Leguizamón, L., \& Castaño, I. (2006). Asociación entre el síndrome de estrés asistencial en residentes de medicina interna el reporte de sus prácticas subóptimas y el reporte de los pacientes. Universitas Psychologica, 5, 549-563

Pineros, M., \& Murillo, R. (2004). Incidencia de cáncer en Colombia: importancia de las fuentes de información en la obtención de cifras estimativas. Revista Colombiana de Cancerología, 8, 5-14.

Rada, V., Garrido, A., Osorio, M., \& Murillo, R. (2004). Anuario Estadistico 2003: por el control del cáncer. Bogotá: Ministerio de Protección Social, Instituto Nacional de Cancerología.

Robles, S., y Galanis, E. (2002). Breast cancer in latin america and the caribbean. Revista Panamericana de Salud Publica, 11, 178-185.

Rodríguez-Marin, J. (1998). Psicología social de la salud. Madrid: Síntesis

Santolaya Ochando, F. J., \& Novoa-Gómez, M. M. (2009). El Rol Del Psicólogo en el Ámbito Hospitalario. En Monsalve, V., Soriano, J., \& Carvajo, E. (edts). Guía Práctica de Psicología de la salud en el ámbito Hospitalario. Valencia: Colegio Oficial de Psicólogos de la Comunidad Valenciana.

Sociedad Americana del Cáncer, (2004). Recursos contra el cáncer laríngeo e hipofaríngeo: Detección y Síntomas, Recuperado en Septiembre 07, 2006 disponible en: http://www2.mdanderson.org/depts/oncolog/sp/ articles/04/10-oct/10-04-1.html

Tomich, P.L., \& Helgeson, V.S. (2002). Five years later: a cross-sectional comparison of breast cancer survivors with healthy women. PsychoOncology, 11, 154-169.

Van der Zee, K., Buunk, B., De Ruiter, J., Tempelaar, R., Van Sonderen, E., \& Sanderman, R. (1996). Social comparison and the subjective well-being of cancer patients. Basic and Applied Social Psychology, $18,453-468$.

Ware, J.E., \& Sherbourne, C.D. (1992). The MOS 36-item short form health survey (SF-36), Medical Care, 30,473-483.

Wiegel R., Macdonald J., Haller D., McDougall I. (2004) Cancer of the endocrine system. En: M, Abeloff, J,Armitage, J, Niederhuber, M, Kastan, W, McKenna, (eds). Clinical Oncology. 3rd ed. Philadelphia, Pa: Elsevier; 1611-1648

World Health Organization. Recuperado en septiembre 15, 2005 disponible en http://www.who.int/publications/es/ 